\title{
Dynamical Model Research on the Enterprise Open Innovation Based on Six
}

\section{Sigma}

\author{
Lijie Feng ${ }^{1}$, Cankun Feng ${ }^{1}$ \\ ${ }^{1}$ College of Management Engineering, Zhengzhou University, Science Road, Zhengzhou, China \\ 772124274@qq.com
}

Keywords: Six sigma, Open innovation, Dynamic model, Innovation model

\begin{abstract}
With the advance of globalization, enterprise innovation model has become a key to continuously enhancing the innovation ability and maintaining the competitive advantage. China is the largest developing country and the local business innovation awareness is generally awakened in recent years, but its innovation capacity las behind the foreign enterprises. The urgent need is to establish an effective innovation model to enhance innovation performance in response to international competition. In view of the existing problems of the current enterprise innovation model, this paper puts forward the dynamic model of open innovation based on the theory of open innovation and the two concrete implementation processes of Six Sigma managements, so as to provide theoretical support for establishing an effective innovation model and creating efficient innovation environment for indigenous enterprises.
\end{abstract}

\section{INTRODUCTION}

In the context of globalization, the emerging new technologies and increasingly diversified customer requirements make the competition between enterprises more and more fierce. Under the enormous competitive pressure, the effective enterprise innovation model enhances the innovation performance of enterprises significantly, so that enterprises could continue to maintain Innovative competitive advantage. With the intensification of international competition, the innovation consciousness of local enterprises in our country is generally enhanced, but the innovation ability, especially the persistent innovation ability, is obviously far from that of foreign enterprises. In the final analysis, enterprise innovation lacks the continuity and system, and the lack of communication between the innovation of various departments is another reason. On the other hand, the ability of Chinese enterprises to use external resources to innovate effectively in order to cope with the increasingly complex external environment needs to be improved. The application of open innovation is basically at the initial stage. In response to these pressing realities, there is an urgent demand for an innovation mode to integrate all the innovative elements of the innovation process in order to improve the innovation performance of the enterprises.

In the era of knowledge economy, enterprises have been difficult to adapt to the rapid development of market demand and increasingly fierce competition only relying on internal resources for high-cost innovation activities. In this context, "open innovation" is gradually becoming the dominant mode of enterprise innovation. Domestic and foreign scholars have made a lot of research on the theory of open innovation. The advocate of open innovation theory, argues that open innovation opens up an innovative external approach that refers to a paradigm that an enterprise uses as an internal innovation resource as an open source for using external innovation resources to improve enterprise innovation(Badawy, 2003). The Open innovation is essentially a traditional open-ended innovation model and the introduction of external innovation capability. With the deepening of the research on open innovation, scholars' attention gradually shifted from the concept of open innovation, the mechanism of influence, the type of open to the application of open innovation. Open innovation is a variety of innovative elements of interaction, integration, coordination of innovative paradigm, its application in the enterprise is a dynamic process(Johannsson, 2015). Open innovation is a dynamic process of interaction, integration and synergy of various innovative elements(Jin, 2006). The open innovation mode of Chinese enterprises is only a simple understanding of the concept and lack of concrete implementation process.

The Six Sigma methodology was created by Motorola in the mid 1980s and it has been developed as measurement system. From the Six Sigma had been conducted as a critical mean help to complete the almost impossible goal at Motorola, the corporate governance began to study their management theory. After this, efficiency of Motorola had begun to be monitored with an index referred as "Sigma Level”(Dahlgaard, 2006). The higher "Sigma Level" means the better customer satisfaction, the more perfect business administration and the stronger enterprise competitiveness(Narasimhan, 2000). In the three-sigma level, the ratio of the acceptable quality is $99.73 \%$. Achieving a Six Sigma level $(6 \sigma)$ of quality means that processes are producing only 3.4 defects per million opportunities(Raisinghani, 2005).

Six Sigma is a management strategy which aims to reducing defects, enhance production, improving the ability meeting customers' requirement and increasing the profit of enterprise(Villa, 2010). Pande et al. provide 
a representative definition of Six Sigma as: A comprehensive and flexible system for achieving, sustaining, and maximizing business success. Six Sigma is uniquely driven by close understanding of customer needs, disciplined use of facts, data, and statistical analysis, and diligent attention to managing, improving, and reinventing business processes(Pande, 2007). Six Sigma is a project-oriented approach which increases the economic profit through quality improvement(Antony, 2002). And Six Sigma project is conducted by an expert group typically referred to Six Sigma management committees, champions, master black belts, black belts, and green belts(Sin, 2015). That's a learning team. In the process of development it formed Six Sigma improvements and design for Six Sigma two important methods(Fukun, 2016).

In this paper, the Six Sigma specific implementation processes are applied to the innovation process of each department. Then the dynamic mode of enterprise open innovation based on Six Sigma is putting forward, which makes technological innovation, management innovation and service innovation to promote the benign interactive benefits and provides a systematic approach for the whole process of continuous innovation. How does the Six Sigma management approaches combine with the open innovation mode? What are the characteristics of this innovative mode? This article will be further elaborated on these issues.

\section{THE ENTERPRISE OPEN INNOVATION SUPPORT SYSTEM}

The enterprise innovation value chain is a parent system composed of various subsystems and the most significant three subsystems are Product R\&D, Production Control and Market Operation. Product R\&D is to explore the potential demand of customers, using the knowledge of science and technology (such as literature, patent, knack) for innovation, which is an activity achieving innovation through the function, structure or product improving. Production Control is the general term composed of various management work which are aimed to establish and operate enterprise manufacture system. Marketing Operation is the activity, set of institutions, and processes for creating, communicating, delivering, and exchanging offerings that have value of customers, clients, partners, and society at large. The three subsystems are closely linked and communicate with each other by product flow, information flow and capital flow. Based on this, they are mutually beneficial and the improvement in any subsystems could promote total performance.

\subsection{Synergy Effect Between Product R\&D and Market Operation}

The Synergy effect between Product R\&D and
Market Operation reflection in that market operation department could take a feedback to Product R\&D department including customer feedback, the market potential of product, distribution capabilities, market service power and so on. It's a vital reference to the choice and direction of Product R\&D. Furthermore, the innovation characteristics of new product are the most important element deciding the market operating strategy. The advantage and the disadvantage of product is the element that must be considered by Market Operating department. Therefore, The Synergy effect between Product R\&D and Market Operation promote and influence each other through the exchange of information.

\subsection{Synergy Effect Between Product R\&D and Production control}

The synergy effect between Product R\&D and Production Control reflection in that Product $R \& D$ department provide the latest product model to Production Control department for directing production. Innovative product is an important element that affects production plan and production organization of Production Control department. Besides, Production Control department influences the choice and direction of Product R\&D through the feedback information including production qualified rate, enterprise production capacity. Consequently, the Synergy effect between Product R\&D and Production Control is a mutually beneficial effect through the optimal choice of Production and R\&D.

\subsection{Synergy Effect Between Market Operation and Production control}

The synergy effect between Market Operation and Production control reflection in that Market Operation take a large extent affect to the production plan, as different product sales determines the different production plan. On the other hand, Production Control department performance determines Market Operation strategy as only special strategy could obtain the best performance according to different production capacity and quality. Thus, the synergy effect between Market Operation and Production Control interact through the product flow in the system.

The synergies between the two companies have a significant impact on the innovation ability of enterprises based on the relationship between product R\&D, production control and market operation. Three departments at the same time open innovation, the effect and promote each other, so that internal and external innovation resources can be fully utilized. Therefore, this paper integrates with the three departments, put forward the enterprise product development, production control and market operations based on the enterprise open innovation model, as shown in Figure 1. 


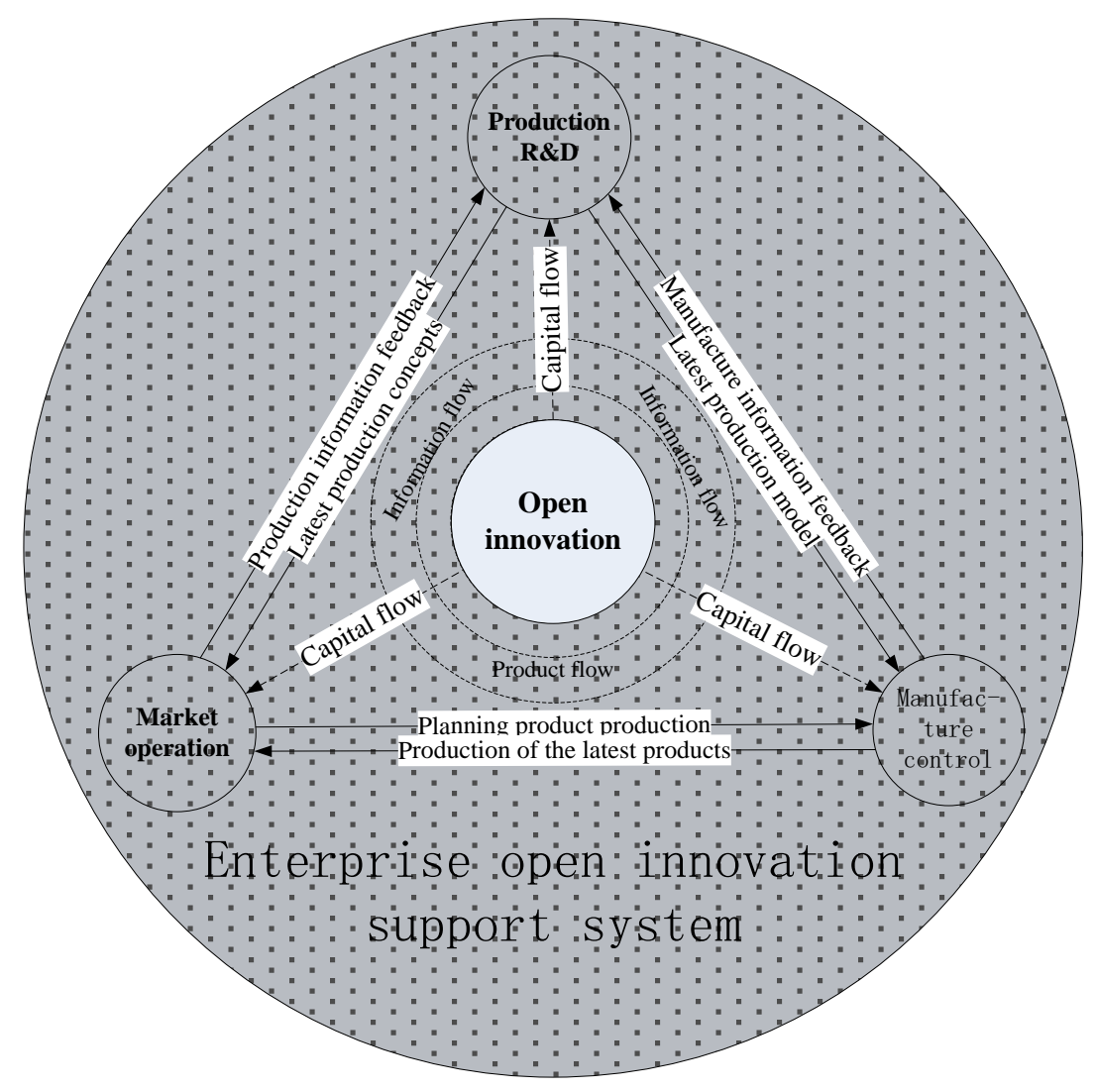

Figure 1: Enterprise open innovation support system

Enterprise open innovation support system possess three characteristics: (1)The system is open and every subsystems can access resources for promoting innovation. (2)The system is a whole and any changes of any subsystems can drive the improvement in the whole system with the flows. (3)The system is circulatory and the subsystems are correlative dependent. Product R\&D, Production Control and Marketing Operation are interdependent and promoting each other in the process of enterprise innovation, they have a close logical relationship and synergy.

\section{DYNAMICAL MODEL OF THE ENTERPRISE OPEN INNOVATION BASED ON SIX SIGMA}

The Six Sigma way is a kind of continuous improvement management method and it has a method (IDDOV process). The Six Sigma improvement is aimed at promoting the process to the Six Sigma quality level by finding and improving the process defects, which focuses on the improvement of existing process, such as production and service departments. The Design For Six Sigma strictly controls the new product from design phase for eliminating possible defects at the source, which is beneficial to reduce cost and improve performance through controlling the mistake before its occurrence. The IDDOV process pays more attention to the design phase or redesign phase of the product or process, which is mostly used to Product $R \& D$ Department. The enterprise open innovation support system provides an important theoretical reference for improving their research and development ability, but in practice the problem is the lack of specific processes and methods. The Six Sigma way is a flexible management method which acquires, maintain and maximize the business success, and it has specific improvement processes could be applied to each link of the enterprise. The following is the application of six sigma methods of every enterprise operation link.

\subsection{The DMAIC Cycle in Manufacture Control Department}

In the enterprise innovation value chain, the application of the DMAIC process in the production control department could continue to improve the product quality and reduce the production cost, which is one of the core power to acquire competitive advantage. The concrete application of six sigma improvement methods in the production control process is as follows: (1)Define phase. Confirming improvement objective, production technological and managing problem. Defining the resources and environment conditions. (2)Measurement phase. It needs set evaluation index system and collect full and accurate key production data aimed to determine or rule out problems and opportunities by reliable and repeatable measurements. (3)Analysis phase. In this phase it need analysis data collected by measuring phase to determine the root cause of the problem. (4)Improvement phase. On the basis of definition, measurement and analysis, improving phase optimizing the production process and production allocation of resources for improving product quality and reducing production cost by putting forward, selecting and implementing solution. (5)Control phase. It effectively controls improvement scheme in order to 
achieve higher levels of optimization. Moreover, it needs ensure a higher management level is continued through
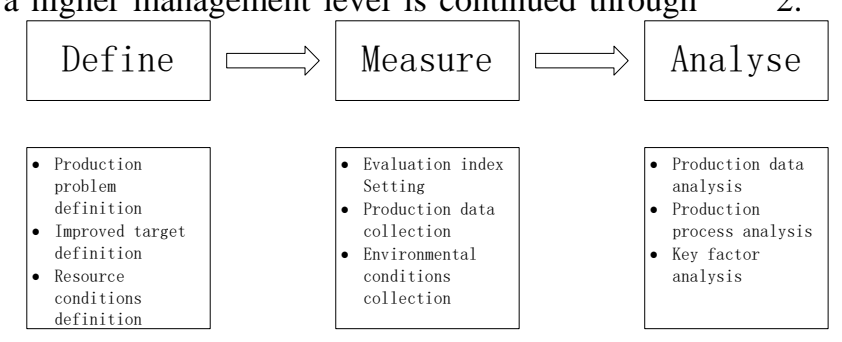

controlling the optimization results. As shown in Figure 2.

Figure 2: The DMAIC cycle in Manufacture Control Department

\subsection{The DMAIC Cycle in Market Operation Department}

Under the background of economic globalization market operation is more and more important to improve enterprise competitiveness, and the process based on service has bigger potential than production process. Therefore, the application of Six Sigma DMAIC process in the process of the market operation is significant. The concrete application of Six Sigma improvement methods in the market operation process are as follows: (1)Define phase. It needs determine product target market, the market operation process problems and the market operation improvement targets by analysing the current situation of enterprise market operation. (2)Measurement phase. According to enterprise's external environment, it needs take detailed market research and gather the information including political, legal and social cultural environment. On the other hand it needs to gather information of competitors and supply chain upstream and downstream. The complexity and competitiveness of the market require the measurements must be accurate, so the comprehensive analysis of next phase draw valid conclusions. (3)Analysis phase. It needs analyze the market development trends and the industry competition trend relying on accurate data and the application of statistical methods, etc. Then according to market research results, it needs analyze consumer preference and psychology. In addition, the optimization of next phase need the fundamental cause which results in the current lower marketing model performance. (4)Improvement phase. In this phase, putting forward, choosing and implementing the optimization schemes of the enterprise marketing model, supply chain management and value network is the primary mission based on the definition, measurement and analysis of market operation process. The purpose is improving market operations innovation effect. (5) Control phase. In this important phase, it needs control the effect of market operation and maintain good brands image and market reputation. Keeping the six sigma improvement achievement is the main task of this phase. As shown in Figure 3.

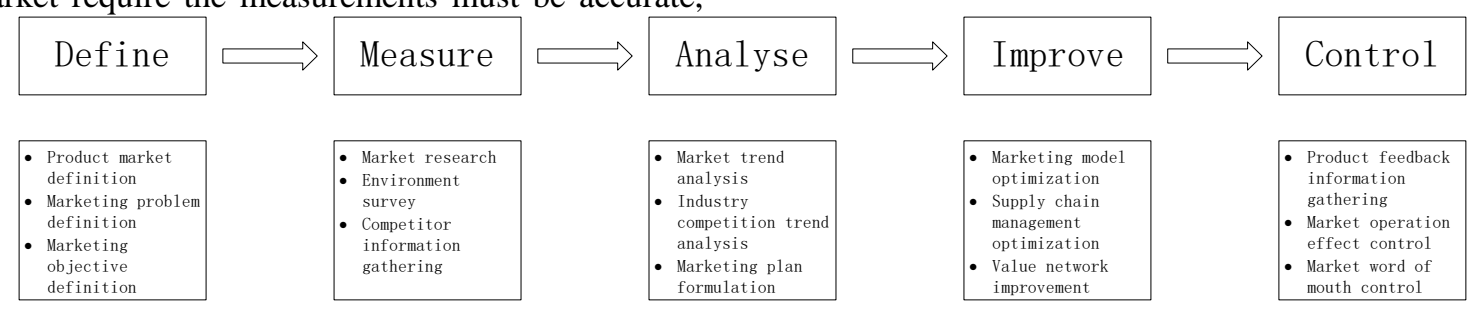

Figure 3: The IDDOV cycle in Product Development Department

\subsection{The IDDOV Cycle in Product Development Department}

Product research and development is the survival foundation of the modern enterprise, but the traditional Product R\&D process cause a lot of resource waste and low efficiency because of lacking attention to the synergy of other enterprise departments. The application of the Design for Six Sigma method to Production R\&D department could minimize possible defects to reduce cast and improve service quality in the resource. (1)Identify phase. First, identifying the customer demand is the basis of product functional design. Second, identifying the market prospect is to find the specific market segment and consumer groups. Third, it needs search for the direction of technological development through identifying technological opportunities. Whether identifying accurately work determines the efficiency of product development process. (2)Define phase. After the identify phase, it need define customer requirements, technical framework, the initial product concept, the technical advantages and defects. (3)Design phase. In this phase, it needs raise and choose the best product design scheme through a series of process including product conceptual design, functional design, process design and prototype design. (4)Optimize phase. The purpose of this phase is optimizing the product design scheme by adjusting to improve the issues of the industrial design and the production process constantly. (5)Verify phase. Finally, the new products need pass the product function test, quality test and safety test for verifying product functionality, reliability and security. Based on the tests, the enterprise decides whether put into production. As shown in Figure 4. 


\begin{tabular}{|c|c|c|c|c|c|c|}
\hline Identify & Define & Design & $\Longrightarrow$ & Optimisize & $\square$ & Verify \\
\hline $\begin{array}{l}\text { - Consumer demand } \\
\text { discovery } \\
\text { - Market prospect } \\
\text { discovery } \\
\text { - Technical } \\
\text { opportunity } \\
\text { discovery }\end{array}$ & \begin{tabular}{|l} 
- Technical \\
framework \\
definition \\
- Technical \\
advantages and \\
disadvantages \\
demarcation \\
- Product concept \\
demarcation
\end{tabular} & $\begin{array}{l}\text { - Product } \\
\text { conceptual design } \\
\text { - Product function } \\
\text { design } \\
\text { - Product process } \\
\text { design } \\
\text { - Product prototype } \\
\text { design }\end{array}$ & & $\begin{array}{l}\text { - Product function } \\
\text { optimization } \\
\text { - Product design } \\
\text { optimization } \\
\text { - Production } \\
\text { process } \\
\text { optimization }\end{array}$ & & $\begin{array}{l}\text { - Product function } \\
\text { testing } \\
\text { - Product quality } \\
\text { testing } \\
\text { - Product safety } \\
\text { testing } \\
\text { - Production } \\
\text { feasibility } \\
\text { validation }\end{array}$ \\
\hline
\end{tabular}

Figure 4: The IDDOV cycle in Product Development Department

\subsection{Dynamical Model of the Enterprise Open Innovation Based on Six Sigma}

In conclusion, this paper combines each part of the enterprise open innovation supporting system, putting forward the dynamical mode research of the enterprise open innovation based on Six Sigma theories. As shown in Figure 5.

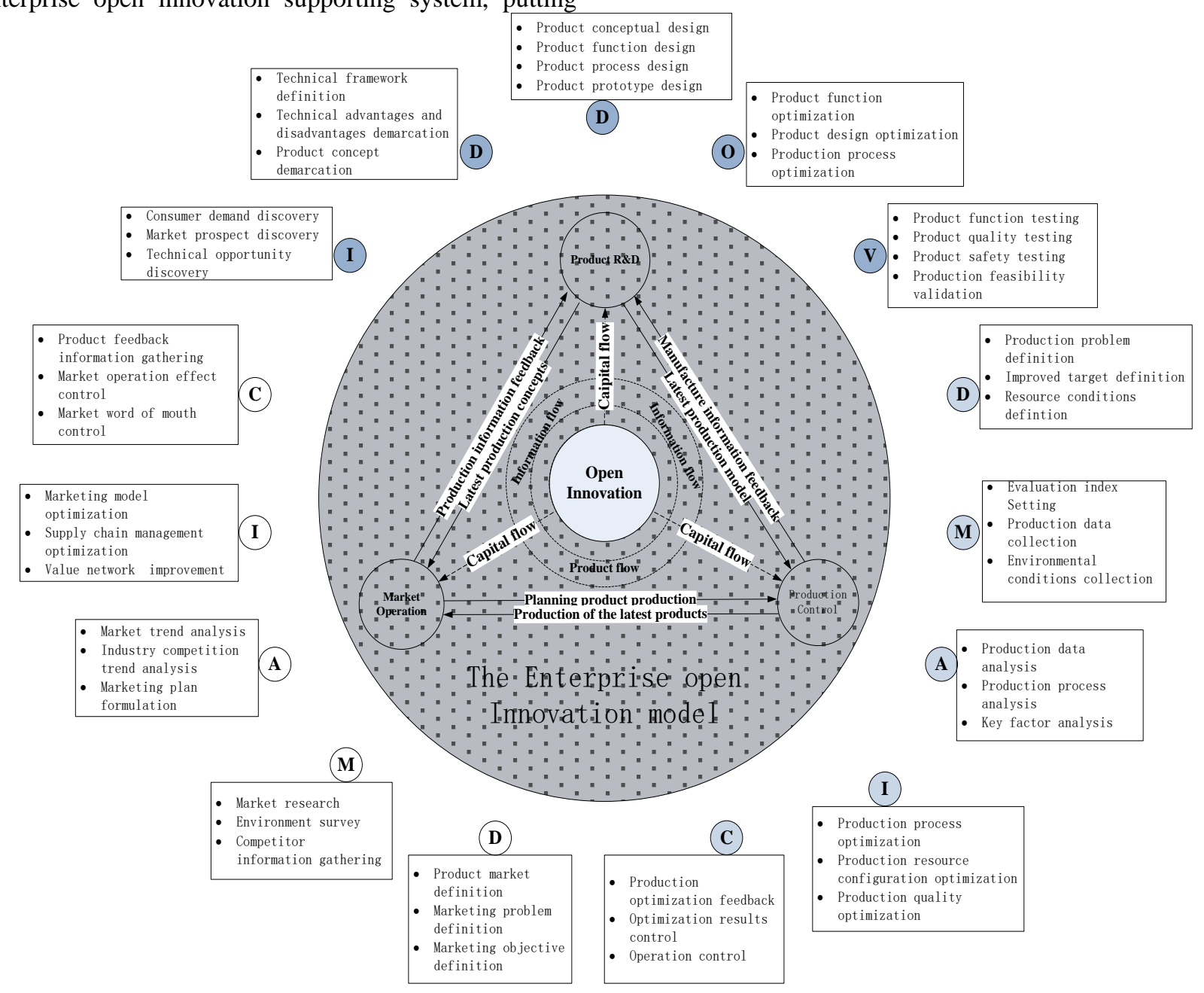

Figure 5: Dynamical model of the enterprise open innovation based on Six Sigma

This model has the following features: (1)The model has the characteristic of integrity. In the enterprise innovation value chain, any phase of any link gets the improvement, which produces impetus through the information flow, product flow and capital flow between every link. (2)The model has the characteristic of continuous improvement, which is derived from the characteristic of the Six Sigma method maintaining longterm success. (3)The model could make use of external resources for open innovation, as enterprise access to resources from the customers, suppliers, dealers, strategic cooperation enterprises for innovation. (4)The model is a method of universal system, which is not only a theoretical research but also an effective method system. It should be noted that the model for different enterprises, each stage of the specific application will be targeted for the specific needs of enterprises have changed, so as to select the most suitable target enterprises to enhance the specific business model innovation performance. It should be noted that the model for different enterprises, each stage of the specific application will be targeted for the specific needs of enterprises have changed, so as to select the most suitable target enterprises to enhance the specific business model innovation performance. 


\section{CONCLUSIONS}

Based on the practical problems of enterprise innovation model, this paper applies the DMAIC process and IDDOV process of Six Sigma to the innovation cycle including enterprise product development department, production control department and operation management department. Then this paper summarizes and puts forward the dynamical mode of the enterprise open innovation based on six sigma theories, with a view to provide theoretical support for the reform of China's enterprises innovation model.

As a whole, this mode has the characteristics of open innovation, innovative dynamic cycle mode and Six Sigma management. The innovation mode can effectively integrate all the innovative elements including the external innovation resources of the enterprise. A variety of innovative elements in accordance with the steps of the Six Sigma process of the cycle of the mode, every point of innovation will promote the innovation of whole process, which makes the formation of continuous effect of dynamic cycle.

There are still some shortcomings in this paper: Our model is only a theoretical mode, and it needs to be indepth case and empirical study to prove the effectiveness of the mode; In addition, the mode is not currently applicable to all enterprises. It is more suitable to the innovation of productive enterprises, and it needs to be further studied for the applications of other types of enterprise.

\section{REFERANCES}

[1] Antony, J., Banuelas, R., 2002. Key ingredients for the effective implementation of Six Sigma program, Measuring Business Excellence. 6(4), pp.20-27.

[2] Badawy, M., 2003. Open innovation: The new imperative for creating and profiting from technology, Journal of Engineering \& Technology Management. 21(3), pp.86-88.

[3] Dahlgaard, J., Su, P., 2006. Lean production, six sigma quality, TQM and company culture, TQM Journal. 18(3), pp.263-281.

[4] Fukun, Wang, Chingtan, Ye, Taopeng, Chu, 2016. Using the design for Six Sigma approach with TRIZ for new product development, Computers \& Industrial Engineering. 98, pp.522530.

[5] Jin, Chen, Yufen Chen, 2006. Open innovation system and enterprise technology innovation resource allocation, Scientific Research Management. (03), pp.1-8.

[6] Johannsson, M., Wen, A., 2015. Space and Open Innovation: Potential, limitations and conditions of success[J]. Acta Astronautica, McGraw-Hill. 115, pp.173-184.

[7] Narasimhan, K., 2002. The six sigma way: How GE, motorola, and other top companies are honing their performance, TQM Journal. 14(4), pp.263.

[8] Pande, S., Robert, P., 2007. The six sigma way, Technometrics. 44(3), pp.299-300.

[9] Raisinghani, S., Ette, H., Pierce, R., 2005. Six sigma: concepts, tools, and applications, Industrial Management \& Data Systems. 105(4), pp.491-505.

[10] Sin, A., Zailani, S., Iranmanesh, M., 2015. Structural equation modelling on knowledge creation in Six Sigma DMAIC project and its impact on organizational performance, International Journal of Production Economics. 168, pp.105117.

[11] Villa, D., 2010. Automation, lean, six sigma: Synergies for improving laboratory efficiency, Journal of Medical Biochemistry. 29(4), pp.339-348. 